\title{
Çevresel Etki Değerlendirmesi Uygulamalarında Enerji Sektörü Analizi
}

\author{
Hakan Ceylan $^{1 *}$ \\ 1* Isparta Uygulamalı Bilimler Üniversitesi, Teknik Bilimler MYO, İş̧aat Bölümü, Isparta, Türkiye, (ORCID: 0000-0001-8099-9819), hakanceylan@isparta.edu.tr
}

(İlk Geliş Tarihi 14 Haziran 2021 ve Kabul Tarihi 28 Ağustos 2021)

(DOI: 10.31590 /ejosat.952538)

\begin{abstract}
ATIF/REFERENCE: Ceylan, H., (2021). Çevresel Etki Değerlendirmesi Uygulamalarında Enerji Sektörü Analizi, Avrupa Bilim ve Teknoloji Dergisi, (27), 237-242.

\section{$\ddot{\mathbf{O z}}$}

Ülkelerin gelişmişlik düzeyinde belirleyici olan enerji yatırımları, ekonomik, siyasal ve çevresel etkileri ile gündemdedir. Özellikle küresel boyutta çevre kirliliklerin arttığı günümüzde enerji üretiminde, fosil yakıtlar yerine yenilenebilir kaynaklara yöneliş zorunlu hale gelmektedir. Son yıllarda ülkemizdeki enerji yatırımları ile ilgili değişiklikler ve çeşitlilikler olduğu gözlemlenmektedir. Çalışma kapsamında Çevre ve Şehircilik Bakanlı̆̆ı'nın 1993-2020 yılları arasındaki Çevresel Etki Değerlendirmesi (ÇED) kararlarından, enerji yatırımlarının durumu araştırılmıştır. Elde edilen verilere göre 6310 ÇED başvurusu içerisinde 1346'sının enerji yatırımları ile ilgili olduğu ve oran olarak \%21'e tekabül ettiği tespit edilmiştir. Enerji yatırımları arasında ise yenilenebilir enerji kaynakları olarak hidro-elektrik santrallerin ilk sırada yer aldığı daha sonra rüzgar enerji santrallerinin ve güneş enerji santrallerinin yer aldığı belirlenmiştir.
\end{abstract}

\section{The Analysis of Energy Sector in Environmental Impact Assessment Practices}

\begin{abstract}
Energy investments, which are determinant in the development level of countries, are on the agenda with their economic, political and environmental effects. Especially in today's world, where environmental pollution is increasing on a global scale, it becomes necessary to turn to renewable resources instead of fossil fuels in energy production. In our country changes and diversities regarding energy investments have been observed recently. In the scope of the study the status of energy investments was investigated from the Environmental Impact Assessment (EIA) decisions of the Ministry of Environment and Urbanization between 1993 and 2020. According to the data obtained, it has been determined that 1346 of 6310 EIA applications are related to energy investments and this ratio corresponds to $21 \%$. Among the energy investments, it was determined that hydro-electric power plants took the first place as renewable energy sources, followed by wind power plants and solar power plants.
\end{abstract}

Keywords: EIA, EIA applications, energy investments.

\footnotetext{
*Sorumlu Yazar: hakanceylan@isparta.edu.tr
} 


\section{Giriş}

İnsanların temel yaşamsal ihtiyaçlarını karşılamada zorunlu olan enerji hep önemli olmuştur. Sanayi Devrimi ile endüstride enerji kullanımının artması nedeniyle önemi daha da artmıştır. Ekonomik büyümeyi sağlama ve küresel ölçekte endüstriyel gelişim için sürdürülebilir koşullarda enerji ihtiyacının karşılanması önemlidir (Dışkaya, 2017). Ülkemizin de kalkınma, toplumsal refahı sağlama gayretleri enerji tüketimini arttırmıştır. $\mathrm{Bu}$ enerji talebinin de gittikçe artacağı tahmin edilmektedir. Yapılan çalışmalara ve hesaplamalara göre gelişmekte olan ülkelerden olan ülkemizde elektrik tüketimi, her yıl \%7-8 oranında artmaktadır. (Özsayın, 2013).

Enerji tüketim miktarları ülkeler için gelişmişliğin bir göstergesi olmakla birlikte enerjinin üretim şekli ve yöntemi de çevresel etkileri açısından önem arz etmektedir. Özellikle fosil yakıtların kullanıldığı enerji üretim santrallerinin sera gazı emisyonlarını arttırması küresel ısınma açısından olumsuz sonuçlara neden olmaktadır. Dünya genelinde enerji ihtiyacının, 2016 y1lı verilerine göre, $\% 33,3$ oranında petrol, $\% 28,1$ oranında kömür, \%24,1 oranında doğalgaz, \%6,9 oranında hidrolik enerji, $\% 4,5$ oranında nükleer enerji ve $\% 3,2$ oranında yenilebilir enerji kaynaklarından sağlandığı belirlenmiştir (Koç vd., 2018). Bu oranlara göre yakın zamana kadar dünya enerji tüketiminin \%85,5'inin fosil yakıtlardan sağlandığı anlaşılmaktadır.

Türkiye enerji üretimini uzun yıllar boyunca ağırlıklı olarak fosil yakıtlardan sağlayan ülkelerden biridir. 2012 yılı verileri enerji üretiminin \%61'ini fosil yakıtlardan elde edildiğini göstermektedir (Say, 2013). Ancak Türkiye, jeotermal enerji kaynakları bakımından dünya genelininin \%8'ine, coğrafyası nedeniyle ciddi bir güneş kaynağına, yerşekilleri ve su kaynakları açısından önemli bir hidrolik ve rüzgâr potansiyeline sahip olması sonucu yenilenebilir enerji kaynaklarının çeşitliliği ve potansiyeli bakımından zengin bir ülkedir. (Koç ve Kaya, 2015). Bu nedenle son yıllarda ülkemizde yenilenebilir enerji kaynaklarının enerji üretiminde payının arttırılması yönünde bir yönelim söz konusudur. Enerji üretiminde fosil yakıtların payının 2019 verilerine göre \%56'ya gerilediği, yenilenebilir enerji kaynaklarının da \%44 oranına ulaştı̆̆ Fosil yakıtlardan enerji üretiminin yaklaşık \%37'si kömür vb. yakıtlardan, \%19'u da doğalgaz santrallerinden elde edilmiştir. Yüzde 44'lük paya sahip yenilenebilir enerji kaynaklarının da yaklaşık olarak \%29,2'si hidroelektrik, \%7,1'i rüzgar, $\% 3,1$ ' $i$ güneş ve $\% 3$ civarı da jeotermal enerji santrallerinden sağlanmıştır (Anonim, 2021). Yenilenebilir enerji kaynaklarının kendi içerisindeki dağılımına bakıldığında, hidroelektrik santrallerin (HES) en büyük paya sahip olduğu ancak rüzgaz ve güneş gibi çevresel etkileri daha az olan kaynaklardan henüz yeterince yararlanılamadığı anlaşılmaktadır.

Ülkelerin endüstrileşme ve gelişme çabaları sonucu çevrede, doğada olumsuz etkiler ortaya çıkmakta, sonradan alınan tedbirler çoğu zaman yetersiz kalmaktadır. Üretim faaliyetlerinin çevrede oluşturacağı istenmeyen etkiler genellikle önceden yeterince değerlendirilmemekte bunun sonucunda olumsuz etkiler artmaktadır. Gelecekte oluşabilecek bu olumsuz çevresel etkileri ortadan kaldırmak ya da en aza indirmek için kullanılacak bazı yöntem ve araçlara ve bunların geliştirilmesine ihtiyaç söz konusudur (Cengiz Gökçe ve Barış, 2015).

Çevresel Etki Değerlendirmesi (ÇED), fiziksel, biyolojik ve beşeri insan faaliyetlerinin çevre üzerindeki etkilerinin değerlendirilmesini içerir. Çoğu ülkede planlama ve kalkınma mevzuatının temel bileşenlerden birini ÇED oluşturmaktadır. (Vatansever Boşça ve Şahin Hamamcı, 2013). ÇED, gerçekleştirilecek faaliyetlerde ileride oluşabilecek çevresel etkilerin planlama aşamasında sistemli bir şekilde araştırılması, değerlendirilmesi, olumsuz etkilerinin önlenmesi, azaltılması için idari açıdan çevre ve doğayı korumak için gerekli kararların alınmasını sağlayan bir araçtır. ÇED sürecinde mümkün olduğu kadar, halkın katılımı toplantıları vasıtasıyla bölge halkı, ilgili kurum ve kuruluşların da katkısı ve görüşlerinin alınması esastır (Yücel, 2001). ÇED, faaliyetlerde oluşabilecek olumsuz çevre ve sağlık etkilerinin önceden belirlenip gerekli tedbirlerin alınmasını amaçlar. ÇED süreci, uzmanlaşmış kişiler tarafından bilimsel metotlarla faaliyetin fiziksel, ekolojik ve sosyoekonomik yönlerinin değerlendirilmesi, şiddetlerinin ve olumsuz etkilere karşı alınacak tedbirlerin belirlenmesi gibi çeşitli bileşenlerden oluşur (Uslu, 1994).

ÇED sürecinde her türlü çevresel etkinin önceden değerlendirmesi yapıldığ 1 için işletmeler için çevresel açıdan topluca bir gözden geçirme yapılmaktadır. Bu değerlendirme sonucunda faaliyetin durumuna göre, oluşabilecek değişik çevresel etkiler belirlenir. Bunun sonucu olarak da işletmeler için çevre açısından hem teknik hem de hukuki olarak birçok yükümlülük taahhüt altına alınmış olur.

ÇED sürecinin planlanan yatırımla ilgili, yöre halkının fikir, görüş, itiraz ve önerilerini önemseyen şeffaf ve demokratik bir yanı söz konusudur. Özellikle halkın katılımı sürecinde konu ile ilgili tüm tarafların ilgili faaliyet hakkında görüş bildirme hakkı mevcuttur. $\mathrm{Bu}$ sürecin iyi değerlendirilmesi, faaliyetin uygulanması aşamasında oluşabilecek olumsuz tepkilerin önlenebilmesi açısından önemlidir. Çünkü faaliyete başlamadan önce, konu ile ilgili taraflar bilgilendirilmekte ve projeye katılımı sağlanmaktadır. Bu bilgilendirmeyle işletme aşamasına geldikten sonra oluşabilecek şikayetlerin de büyük oranda önlenmesi söz konusudur.

Gerçekleştirilecek faaliyetlerde korumacı bir yaklaşımla çevre kirliliği oluşmadan önce önlem alınması daha az maliyet gerektirir. Zira çevre kirliliği oluştuktan sonra temizlenmesi, eski haline getirilmesi hem daha zor hem de maliyeti çok yüksek olmaktadır. ÇED süreci sadece hukuki bir zorunluluk olarak görülmemeli, aynı zamanda hem faaliyetin ekonomik ve teknik olarak sürdürülebililirliği hem de bizden sonraki kuşaklara yaşanılabilir bir çevre bırakmak için kullanılan bir çevre yönetim aracı olarak görülmelidir (Turan ve Güner, 2017).

ÇED 50 yıla yakın süredir öncelikle $A B D$ ve $A B$ ülkeleri olmak üzere dünyada uygulanmakta olan en etkin çevre yönetim araçlarından biridir (Dikmen, 2019). ÇED dünyada ilk olarak 1970 yılında ABD’nde yürürlüğe girmiş, bunu Kanada, Batı Almanya, Fransa gibi gelişmiş ülkeler izlemiştir.

Türkiye'de ise 1993 yılında Çevre Kanunu'nun 10. maddesine dayanılarak çıkarılan bir yönetmelikle uygulanmaya başlanmış ve yasal bir zorunluluk haline gelmiştir. ÇED Yönetmeliği'nin ekinde ÇED'e tabi olan faaliyetler EK-I ve EKII olarak 2 kısımda verilmektedir. Genel olarak çevresel etkileri daha fazla olan, kapasiteleri yüksek faaliyetler EK-1'de yer almaktadır. Bu faaliyetlerde ÇED raporu hazırlanması gerekliliği vardır. ÇED Raporunun Çevre ve Şehircilik Bakanlığı'nca değerlendirilmesi sonucunda "Çevresel Etki Değerlendirmesi Olumlu” veya "Çevresel Etki Değerlendirmesi Olumsuz” kararı verilir. EK-II'de ise EK-I'deki faaliyetlerden daha küçük faaliyet ve işletmeler yer almaktatır. EK-II'deki işletmelerden proje tanitım dosyası istenir. $\mathrm{Bu}$ dosyada faaliyetle ilgili 
kapasite, kullanılan teknoloji, oluşacak atıkların türü ve miktarı, atıkların bertaraf şekli, faaliyet alanına ilişkin çevresel özellik vb. bilgiler verilir. EK-II'deki faaliyetlerle ilgili olarak proje tanıtım dosyasının incelenmesi sonucunda, "Çevresel Etki Değerlendirmesi Gereklidir" veya "Çevresel Etki Değerlendirmesi Gerekli Değildir" kararı verilmektedir. Bu karar da yönetmeliğe göre Çevre ve Şehircilik Bakanlığı'nca verilmektedir Ancak Bakanlık bu yetkiyi Valiliklere devredilebilmektedir.

ÇED Yönetmeliği ek kısmında ÇED raporu formatı verilmektedir. ÇED raporunda faaliyetle ilgili iş akım şeması, kapasite, kullanılanak alan, çalışan sayısı, kullanılacak teknoloji vb. konularda bilgi verilir. Ayrıca, arazi kullanımına göre proje etki alanı net olarak belirtilir. Proje kapsamında Ek V Duyarlı Yöreler Listesi içerisinde kalan alan varsa ayrıntılı olarak incelenir ve belirtilir. Proje alanındaki vejetasyon tipinin, grid sistemine göre hangi karede yer aldığı belirtilir. Proje etki alanının flora-fauna açısından incelenmesi, varsa ulusal ve uluslararası koruma altına alınmış endemik türlerin belirlenmesi ve envanterinin çıkarılması gerekir. Ayrıca projeden etkilenecek flora-faunayı korumak için alınacak önlemlerin açıklanması gerekmektedir.

Faaliyetin çevre üzerine etkilerinin belirlenmesi amacıyla, projedeki doğal kaynak kullanımı, yapılacak örtü kazı miktarı ve bunun nerede ve nasıl depolanacağı, tesiste kullanılacak içme, kullanma suyu miktarı, suyun nereden ve ne şekilde sağlanacağının belirtilmesi gerekir. Ayrıca tesiste oluşacak atık türleri (katı atık, sıvı atık, toz vb.), bu atıkların muhtemel olarak miktarları ilgili yönetmeliklere göre değerlendirilerek verilmedir. İşletmede kullanılacak teknoloji ve malzemeler ayrıntılı olarak belirtilerek bunlara bağlı oluşabilecek kazalara karşı alınacak önlemler belirtilir.

Projenin olası çevresel etkileri belirlendikten sonra, bu çevresel etkilerin en aza indirilmesi veya tamamen önlenmesi için yapılacak işlemler, doğaya geri kazanım ile ilgili bilgiler ayrıntılı olarak verilir.

Son olarak projenin genel bir değerlendirmesi yapılarak 2872 sayılı Çevre Kanunu ve ilgili yönetmelikler ile diğer mevzuatlar kapsamında gerekli her türlü izinlerin alınacağı ve ilgili yönetmeliklere uyulacağı taahhüt edilir.

Enerji yatırımları büyük ve çevresel etkileri önemli olması nedeniyle ÇED sürecine tabi faaliyetlerdir. ÇED Yönetmeliği ek kısmında ÇED sürecine tabi olan enerji yatırımları aşağıda verilmiştir (Anonim, 2014):

\section{EK-I'deki Enerji Yatırımları:}

- Termik santraller:

- Termik santraller ve diğer yakma sistemleri (Isıl gücü $\geq 300$ MWt olanlar)

-Nükleer santraller veya diğer nükleer reaktörlerin kurulması veya sökümü (maksimum gücü sürekli termik yük bakımından 1 kilovatı aşmayan, atom çekirdeği parçalanabilen ve çoğalan maddelerin dönüşümü, üretimi amaçlı araştırma projeleri hariç)

- Hidroelektrik santraller ( $\geq 10 \mathrm{MWm}$ olanlar)

- Rüzgar enerji santralleri ( $\geq 50 \mathrm{MWm}$ olan veya türbin sayısı 20 adet ve üzerinde olanlar)

- Jeotermal kaynağın çıkartılması ve kullanılması ( $\geq 20 \mathrm{MWe}$ olanlar)

- Güneş enerji santralleri ( $\geq 10$ MWe olan veya proje alanı 20 hektar ve üzerinde olanlar)
- Elektrik enerjisi iletim hatları ( $\geq 154 \mathrm{kV}$ (Kilovolt) gerilimde ve uzunluğu $\geq 15 \mathrm{~km}$ ve üzeri olanlar)

\section{EK-II'deki Enerji Yatırımları:}

- Elektrik enerjisi iletim hatları (uzunluğu 5-15 km ve üzeri ve $\geq 154 \mathrm{kV}$ (Kilovolt) gerilimde olanlar)

- Hidroelektrik santraller (1-10 MWm olanlar)

- Rüzgar enerji santralleri ( $\geq 10 \mathrm{MWm}$ olan veya türbin sayısı 5 adet ve üzerinde olanlar)

- Jeotermal kaynağın çıkartılması ve kullanılması ( $\geq 5$ MWe olanlar)

- Güneş enerji santralleri ( $\geq 1$ MWe olan veya proje alanı 2 hektar ve üzerinde olanlar-cephe ve çatı sistemleri hariç)

ÇED başvurularının incelenmesi ve analiz edilmesi sonucu, ülkelerin endüstriyel gelişimi, bunun yillar içerisindeki yöneliş eğilimleri, ülke içindeki bölgesel endüstriyel yatırım farklılıkları, kalkınma eğilimleri vb. hususlarda dolaylı olarak da olsa çeşitli bilgiler edinilebilmektedir. Türkiye'de de 1993 yılından beri çeşitli revizyonlar geçirerek uygulanan ÇED Yönetmeliği günümüz ihtiyaçlarına yanıt verme yolunda gelişim göstermektedir. 1993 yılından bu yana bakıldığında ÇED kararlarının her yıl arttığı anlaşılmaktadır (Salihoğlu, 2013). Bu çalışmada da ülkemizdeki ÇED başvuruları ile ilgili kararlar incelenmiş ve enerji yatırımları açısından analiz edilmiştir. Enerji yatırımlarının çeşitlliliği, yönelimleri ve özellikle yenilenebilir enerji kaynak yatırımlarının durumu, sayıları belirlenmeye çalışılmıştır.

\section{Materyal ve Metot}

Çalışmada 1993-2020 yılları arasında Çevre ve Şehircilik Bakanlığı'na EK-I kapsamında Çevresel Etki Değerlendirmesi için başvuru yapan işletmeler arasında enerji yatırımları ile ilgili olanlar incelenerek ÇED başvurularının türü, yılı, illere göre dağılımı ve sonuçları araştırılmıştır.

Çevre Şehircilik Bakanlığı ÇED Genel Müdürlüğü'nden alınan ham veriler analiz edilerek enerji yatırımlarının oranı, olumlu, olumsuz sonuçlanan ve/veya iptal edilen ÇED başvurularında enerji yatırımlarının durumu, enerji yatırımları arasında kendi içerisinde çeşitlilik dağılım oranları, olumsuz sonuçlanan veya iptal edilen enerji yatırımlarının türü istatistiki olarak analiz edilmiştir. Çalışmada, elde edilen sayısal verilerden Türkiye'nin enerji yatırımlarının çeşitliliği, yönelimi ve uygulanan ÇED süreçleri ile ilgili bilgiler elde edilmeye çalışılmıştır.

\section{Araştırma Sonuçları ve Tartışma}

Araştırma kapsamında 1993-2020 yılları arasında, Çevre ve Şehircilik Bakanlığı'na 6310 ÇED başvurusu olduğu belirlenmiştir. $\mathrm{Bu}$ başvurulardan 559'u olumsuz sonuçlanmış olup oran olarak $\% 8,8$ 'e tekabül etmektedir. $\mathrm{Bu}$ olumsuz sonuçlanan başvuruların büyük bölümü ise mevzuata uygun olmamasından kaynaklanmaktadır. Araştırmadaki tüm bulgular Çevre ve Şehircilik Bakanlığı'ndan verilerinden elde edilmiştir (Anonim, 2020).

Tablo 1. ÇED başvurularında enerji yatırımlarının yeri

\begin{tabular}{|l|c|c|}
\hline Sektör & ÇED Başvuru Sayısı & Oranı (\%) \\
\hline Enerji Yatırımları & 1346 & 21 \\
\hline Diğer Sektörler & 4964 & 79 \\
\hline TOPLAM & 6310 & 100 \\
\hline
\end{tabular}


Tablo 1'de verilen Bakanlık verilerine göre, 01.01.2020 tarihine kadar EK-I listesinde olan toplam 6310 adet ÇED başvurusunun 1346'sının enerji yatırımları ile ilgili olduğu tespit edilmiştir. Enerji yatırımlarının toplam başvurular içerisindeki oran $\% 21$ 'dir.

Tablo2. ÇED başvurularında enerji yatırımlarının yıllara göre dağılımı

\begin{tabular}{|c|c|}
\hline Yillar & Başvuru Sayıs1 \\
\hline 1993 & 0 \\
\hline 1994 & 3 \\
\hline 1995 & 3 \\
\hline 1996 & 2 \\
\hline 1997 & 3 \\
\hline 1998 & 4 \\
\hline 1999 & 13 \\
\hline 2000 & 23 \\
\hline 2001 & 23 \\
\hline 2002 & 17 \\
\hline 2003 & 14 \\
\hline 2004 & 18 \\
\hline 2005 & 17 \\
\hline 2006 & 17 \\
\hline 2007 & 41 \\
\hline 2008 & 59 \\
\hline 2009 & 58 \\
\hline 2010 & 87 \\
\hline 2011 & 80 \\
\hline 2012 & 126 \\
\hline 2013 & 150 \\
\hline 2014 & 139 \\
\hline 2015 & 84 \\
\hline 2016 & 83 \\
\hline 2017 & 96 \\
\hline 2018 & 96 \\
\hline 2019 & 90 \\
\hline TOPLAM & 1346 \\
\hline
\end{tabular}

Tablo 2'de ÇED başvurusu yapılmış enerji yatırımlarının yıllar içerisindeki dağılımı verilmiştir. Tablo 2'deki verilerden enerji yatırımları ile ilgili başvuruların 2000'li yıllarda artmaya başladığı, 2013 yılında ise 150 başvuru ile en yüksek değere ulaştığ 1 anlaşılmaktadır. 2015 yılından itibaren 100'ün altına düşse de 90'lı rakamlarda seyrettiği görülmektedir. $\mathrm{Bu}$ rakamlardan enerji yatırımlarının son yıllarda sayı olarak artış göstermese de süreklilik gösterdiği anlaşılmaktadır.

Tablo 3'te ise ÇED başvurusu yapılmış enerji yatırımlarının illere göre dağılımı görülmektedir. Tablo 3'e göre enerji yatırımları ile ilgili başvuru sayılarında Adana ve Artvin 64 başvuru ile 1. sırada yer almaktadır. İzmir 48 başvuru ile 2. sırada, Antalya'nın ise 44 başvuru ile 3. sırada olduğu görülmektedir. Enerji yatırımları açısından en az ÇED başvurusu ise 1 başvuru ile Sinop, daha sonra 2'şer başvuru ile Aksaray, Iğdır, Kilis ve Niğde illerinden yapılmıştır. Ayrıca 81 ilin tamamında enerji sektörü ile ilgili ÇED başvurusu olduğu görülmektedir.

Tablo3. ÇED başvurularında enerji yatırımlarının illere göre dă̆llımı

\begin{tabular}{|c|c|c|c|}
\hline Şehir & Say1 & Şehir & Say1 \\
\hline Adana & 64 & İstanbul & 21 \\
\hline Adiyaman & 14 & İzmir & 48 \\
\hline Afyon & 15 & Kahramanmaraş & 22 \\
\hline Ăgrn & 9 & Karabük & 8 \\
\hline Aksaray & 2 & Karaman & 21 \\
\hline Amasya & 10 & Kars & 11 \\
\hline Ankara & 35 & Kastamonu & 27 \\
\hline Antalya & 44 & Kayseri & 18 \\
\hline Ardahan & 10 & Kirıkkale & 12 \\
\hline Artvin & 64 & Kirklareli & 21 \\
\hline Aydin & 34 & Kırşehir & 3 \\
\hline Balıkesir & 28 & Kilis & 2 \\
\hline Bartın & 9 & Kocaeli & 13 \\
\hline Batman & 12 & Konya & 24 \\
\hline Bayburt & 4 & Kütahya & 7 \\
\hline Bilecik & 7 & Malatya & 13 \\
\hline Bingöl & 25 & Manisa & 31 \\
\hline Bitlis & 13 & Mardin & 6 \\
\hline Bolu & 9 & Mersin & 29 \\
\hline Burdur & 4 & Muğla & 17 \\
\hline Bursa & 24 & Muş & 5 \\
\hline Çanakkale & 37 & Nevşehir & 7 \\
\hline Çankırı & 12 & Niğde & 2 \\
\hline Çorum & 6 & Ordu & 25 \\
\hline Denizli & 13 & Osmaniye & 4 \\
\hline Diyarbakır & 11 & Rize & 31 \\
\hline Düzce & 13 & Sakarya & 12 \\
\hline Edirne & 6 & Samsun & 14 \\
\hline Elaziğ & 18 & Siirt & 18 \\
\hline Erzincan & 18 & Sinop & 1 \\
\hline Erzurum & 42 & Sivas & 21 \\
\hline Eskişehir & 5 & Şanliurfa & 14 \\
\hline Gaziantep & 8 & Şırnak & 14 \\
\hline Giresun & 37 & Tekirdağ & 16 \\
\hline Gümüşhane & 12 & Tokat & 21 \\
\hline Hakkari & 12 & Trabzon & 18 \\
\hline Hatay & 19 & Tunceli & 4 \\
\hline Iğdır & 2 & Uşak & 6 \\
\hline Isparta & 7 & Van & 15 \\
\hline Zonguldak & 12 & Yalova & 5 \\
\hline Yozgat & 13 & TOPLAM & 1346 \\
\hline
\end{tabular}


Tablo 4. ÇED başvurularında enerji sektörü içindeki dă̆ılım

\begin{tabular}{|c|c|}
\hline Tür & Sayı \\
\hline Hidroelektrik Santrali (HES) & 544 \\
\hline Enerji İletim Hattı (EİH) & 280 \\
\hline Rüzgar Enerjisi Santrali (RES) & 145 \\
\hline Doğalgaz Santrali & 68 \\
\hline Güneş Enerjisi Santrali & 40 \\
\hline Elektrik Enerjisi Üretim Tesisi & 40 \\
\hline Baraj ve Sulama & 100 \\
\hline Jeotermal Santrali & 30 \\
\hline Kömür & 13 \\
\hline Atık Geri Kazanım Tesisi & 13 \\
\hline Kül Depolama & 16 \\
\hline Diğer & 57 \\
\hline TOPLAM & 1346 \\
\hline
\end{tabular}

ÇED başvuruları arasında \%21'lik dilime sahip enerji yatırımlarının sektör içerisindeki tür dağılımı ise Tablo 4'deki gibidir. Verilere göre en çok hidroelektrik santrali, daha sonra enerji iletim hattı ve rüzgar enerji santrali yatırımları için ÇED başvurusu yapıldığı anlaşılmaktadır. Yenilenebilir enerji kaynakları olarak rüzgar enerji santralleri ÇED başvuruları arasında 3. sırada yer alırken kömür ile ilgili sadece 13 ÇED başvuru yapılmış olması dikkat çekicidir. $\mathrm{Bu}$ verilere göre yenilenebilir enerji yatırımlarında bir artış olduğu görülmektedir. Ayrıca önemli bir fosil yakıt olan kömürle ilgili yeni yatırımların azaldığ 1 anlaşılmaktadır.

Enerji yatırımları ile ilgili ÇED başvurularının 112'si olumsuz sonuçlanmıştır. Bunların 109'u mevzuata uygun bulunmadığ olmadığ için olumsuz sonuçlanmıştır. Bu rakamlara göre enerji ile ilgili ÇED başvurularının \% 8,3'ünün olumsuz sonuçlandığ anlaşılmaktadır.

Tablo 5. Enerji sektöründe olumsuz sonuçlanan ÇED başvurularında tür dağılımı

\begin{tabular}{|l|c|}
\hline Tür & Say1 \\
\hline Hidroelektrik Santrali & 56 \\
\hline Rüzgar Enerjisi Santrali & 18 \\
\hline Güneş Enerjisi Santrali & 4 \\
\hline Termik Santral & 23 \\
\hline Doğalgaz Santrali & 3 \\
\hline Atık Geri Kazanım Tesisi & 4 \\
\hline Jeotermal Santrali & 1 \\
\hline Kömür Santrali & 1 \\
\hline Diğer & 2 \\
\hline TOPLAM & 112 \\
\hline
\end{tabular}

Tablo 5'de enerji sektörüne ait olumsuz sonuçlanan ÇED başvurularının türe göre sayıları verilmektedir. Hidroelektrik santrali yatırımlarına ait Tablo 4'de görülen 544 ÇED başvurusunun 56'sının olumsuz sonuçlandığ görülmektedir. Daha sonra 2. sirada 23 termik santral ve 3 . sirada 18 rüzgar enerji santrali başvurusunun olumsuz sonuçlandığ belirlenmiştir.

\section{Sonuç}

ÇED başvurularına ait verilerin analiz edilmesi sonucunda aşağıdaki sonuçlara ulaşılmıştır:

1993-2020 yılları arasında Çevre ve Şehircilik Bakanlığı'na 6310 ÇED başvurusu yapılmış bunlardan 559'u olumsuz sonuçlanmıştır. Başvuruların \%91,2'si olumlu olarak sonuçlandığı belirlenmiştir.

Toplam 6310 ÇED başvurusu içerisinde 1346'sının enerji yatırımları ile ilgili olduğu ve oran olarak \%21'e tekabül ettiği tespit edilmiştir.

Enerji yatırımları ile ilgili ÇED başvurularının 2000'li yıllarda artmaya başladı̆̆ı, 2013 yılında ise 150 başvuru ile en yüksek değere ulaştığı, 2015 yılından itibaren 100'ün altına düşse de 90'lı rakamlarda seyrettiği ve günümüze kadar süreklilik gösterdiği anlaşılmaktadır.

Enerji yatırımları ile ilgili ÇED başvuru sayılarında Adana ve Artvin 64 başvuru ile 1. sırada, İzmir 48 başvuru ile 2. sırada, Antalya ise 44 başvuru ile 3. sırada yer almaktadır. En az başvuru ise 1 başvuru ile Sinop, daha sonra 2'şer başvuru ile Aksaray, Iğdır, Kilis ve Niğde illerinden yapılmıştır. Ayrıca 81 ilin tamamından başvuru olduğu görülmektedir.

Bulgulara göre en çok hidroelektrik santrali, daha sonra enerji iletim hattı ve rüzgar enerji santrali yatırımları için ÇED başvurusu yapıldığı anlaşılmaktadır. Yenilenebilir enerji kaynakları olarak rüzgar enerji santrallerinin ÇED başvuruları arasında 3. sırada yer aldığı belirlenmiştir. Kömür ile ilgili sadece 13 ÇED başvuru yapılmış olması, enerji üretiminde fosil yakıta dayalı yatırımların nispeten azaldığını göstermektedir. $\mathrm{Bu}$ rakamlar da ülkemizde enerji yatırımlarının fosil yakıtlardan yenilenebilir kaynaklara yöneldiğini göstermektedir.

Enerji yatırımları ile ilgili ÇED başvurularının \% 8,3'ünün olumsuz sonuçlandığı belirlenmiştir. Enerji yatırımlarının olumsuz sonuçlanma oranı, tüm ÇED başvurularının olumsuz sonuçlanma oranı olan \% 8,8'e çok yakındır. Yani enerji yatırımlarına ait ÇED başvurularının olumsuz sonuçlanma oranı, genel ÇED başvurularının olumsuz sonuçlanma oranlarına paralellik göstermektedir.

Enerji sektörüne ait olumsuz sonuçlanan 112 ÇED başvurusunun 56'sının hidroelektrik santrali, 23 'nün termik santral ve 18'inin rüzgar enerji santraline ait olduğu tespit edilmiştir. Bu rakamlar da ülkemizde ÇED sürecinin önemini ve işlevini yerine getirdiğini göstermektedir.

\section{Kaynakça}

Anonim, (2019). Çevresel Etki Değerlendirmesi (ÇED) Yönetmeliği. Resmî Gazete, 25.11.2014, Sayısı: 29186

Anonim, (2020). ÇED kararları, 10.01.2020, https://ced.csb.gov.tr/

Anonim, (2021).Yillik enerji üretiminin kaynaklara göre dağılımı, 09.06.2021, https://www.enerjiatlasi.com/elektrikuretimi/)

Cengiz Gökçe, G., Barış, M.E. (2015). Çevresel Etki Değerlendirmesi (ÇED)- Stratejik Çevresel Değerlendirme (SÇD) ilişkisi ve peyzaj planlama sürecinde stratejik çevresel değerlendirmenin önemi, International Journal of 
Science Culture and Sport, Özel Say1 3, 782-792. DOI: 10.14486/IJSCS345

Dışkaya, S.K. (2017). Türkiye'nin enerji güvenliğinde yenilenebilir enerji etkisinin politik ekonomi perspektifi, Marmara Üniversitesi Siyasal Bilimler Dergisi, 5(2), 129150. DOI: $10.14782 / \mathrm{sbd} .2017 .69$

Dikmen, A.Ç. (2019). Stratejik Çevresel Değerlendirme (SÇD) Yönetmeliği'nin Türkiye'nin çevre politikasına katkısı, Avrupa Bilim ve Teknoloji Dergisi, (15), 535-541. DOI: 10.31590/ejosat.532951

Koç, A., Yağli, H., Koç, Y., Uğurlu, İ. (2018). Dünyada ve Türkiye'de enerji görünümünün genel değerlendirilmesi, Mühendis ve Makine, 59(692), 86-114.

Koç, E., Kaya, K. (2015). Enerji kaynakları-yenilenebilir enerji durumu, Mühendis ve Makina, 56(668), 36-47.

Özsayın, S. (2013). Enerji Alternatiflerinin Çevre ile Etkileşimi, T.C. Çevre Bakanlığ Uluslararası ÇED Kongresi, 287-299.

Salihoğlu, G., (2013). Sayılarla Türkiye'de alınan ÇED kararları, T.C. Çevre Bakanlığı Uluslararası ÇED Kongresi, 67-74.

Say, N.(2013). Enerji politikaları ve SÇD: Türkiye örneği, T.C. Çevre Bakanlı̆̆ı Uluslararası ÇED Kongresi, 265-278.

Turan, E.S., Güner, E.D. (2017). Türkiye'de Çevresel Etki Değerlendirme mevzuatındaki değişimler, Doğal Afetler ve Çevre Dergisi, 3(1), 39-47. DOI: 10.21324/dacd.286187

Uslu, O. (1994). ÇED eğitimi, Çevre kavramına genel bakış, Türkiye Çevre Vakfı Yayını, Önder Matbaası, Ankara.

Vatansever Boş̧̧a, A., Şahin Hamamcı, N. (2013). Kümülatif Çevresel Etki Değerlendirmesi, T.C. Çevre Bakanlı̆̆ Uluslararası ÇED Kongresi, 33-47.

Yücel, M. (2001). Çevresel Etki Değerlendirmesi, Baki Kitabevi, Adana. 